\title{
Morphological and Optical Characteristics of Porous Silicon Produced by Anodization Process in HF-Acetonitrile and HF-Ethanol Solutions
}

\author{
Cláudia R. B. Miranda,* Maurício R. Baldan, Antonio F. Beloto \\ and Neidenêi G. Ferreira
}

Instituto de Pesquisas Espaciais, Laboratório Associado de Sensores e Materiais, INPE/LAS, Avenida dos Astronautas 1758, Jardim da Granja, CP 515, 122245-970 São José dos Campos-SP, Brazil

\begin{abstract}
Amostras de silício poroso (PS) foram obtidas pelo processo de anodização em lâminas de Si tipo n, dopadas com fósforo. A oxidação eletroquímica do PS foi obtida utilizando-se solução de ácido fluorídrico (HF) contendo aditivos como etanol e acetonitrila $(\mathrm{MeCN})$. A formação dos poros foi estudada com a variação da resistividade das laminas de Si e parâmetros de processo como: concentração do ácido, densidade de corrente e tempo de anodização. As técnicas de Microscopia Eletrônica de Varredura (MEV) e Espectroscopia de Espalhamento Raman foram utilizadas para a investigação da morfologia e fotoluminescência, respectivamente. A camada de PS formada com o uso da solução de HF-MeCN mostrou maior uniformidade e homogeneidade na distribuição dos macroporos com diferentes tipos e tamanhos. Esse comportamento pode ser explicado devido a tensão superficial da $\mathrm{MeCN}$ ser maior que a do etanol. Consequentemente, as moléculas de $\mathrm{MeCN}$ podem passivar a superfície do silício durante o processo de anodização.
\end{abstract}

Porous silicon (PS) samples were obtained by anodization etching process of n-type silicon wafer phosphorus-doped. Electrochemical oxidation of PS was investigated in aqueous hydrofluoric acid (HF) containing additive such as ethanol or acetonitrile. Pore formation was studied with the variation of type and resistivity of the silicon wafer, taking into account the most important anodization process parameters such as: acid concentration, current density and anodization time. Scanning Electron Microscopy (SEM) and Raman Scattering Spectroscopy measurements were used to characterize the macropore morphology changes and sample photoluminescense responses, respectively. PS layer formed in HF-acetonitrile solution showed more uniform and homogeneous macropore distributions with different shapes and sizes. Behavior may be explained because acetonitrile surface tension is greater than that of ethanol. Therefore, acetonitrile molecules might passivate the silicon surface dissolved during the anodization process.

Keywords: porous silicon, HF-acetonitrile, HF-ethanol

\section{Introduction}

Since the discovery of its visible photoluminescence (PL) at room temperature, porous silicon (PS) has been intensively studied. Nowadays, PS is considered a very attractive material for the sensing layer in a chemical sensor, sacrificial layer in micromachining, and light emitting diode (LED) in optoelectronic devices. ${ }^{1-4}$

Porous Si might be formed by electrochemical etching of single monocrystalline $\mathrm{Si}$ in HF solutions containing additives as ethanol or acetonitrile $(\mathrm{MeCN})$. However, the anodization process was firstly studied by Bomchil

*e-mail: claudia@las.inpe.br et al., ${ }^{5}$ in 1983, using HF and ethanol solution and they reported that ethanol improved the homogeneity of PS layer. Consequently, HF-ethanol has been used by most research groups as the standard electrolyte for PS formation process. After that, Propst et al. ${ }^{6}$ have reported the electrochemical oxidation of $\mathrm{p}$ - and $\mathrm{n}$-type silicon in nonaqueous electrolyte of HF-MeCN and discussed their singular and large porous structure.

Although PS layers were studied intensively, there are still questions about the dissolution chemistry of $\mathrm{Si}$, and different mechanisms have been proposed. ${ }^{7.8}$ In general, it is discussed and accepted in the literature that holes $(\mathrm{h}+)$ are required for both electropolishing and pores formation, where two hydrogen atoms are evolved for 
each dissolved $\mathrm{Si}$ atom. ${ }^{7}$ As a consequence, for the pore formation process, the current efficiencies are due to two electrons per dissolved $\mathrm{Si}$ atom, whereas four electrons are necessary for the electropolishing regime. ${ }^{8,9}$ In this sense, the global anodic half-reactions during the pore formation may be written as: ${ }^{7}$

$\mathrm{Si}+6 \mathrm{HF} \rightarrow \mathrm{H}_{2} \mathrm{SiF}_{6}+\mathrm{H}_{2}+2 \mathrm{H}^{+}+2 \mathrm{e}^{-}$

and during electropolishing as: ${ }^{7}$

$\mathrm{Si}+6 \mathrm{HF} \rightarrow \mathrm{H}_{2} \mathrm{SiF}_{6}+4 \mathrm{H}^{+}+4 \mathrm{e}^{-}$

The final and stable product for $\mathrm{Si}$ in $\mathrm{HF}$ for both cases is $\mathrm{H}_{2} \mathrm{SiF}_{6}$ or some of its ionized forms. This means that during the pore formation only two of the four available $\mathrm{Si}$ electrons participate in an interfacial charge transfer, while the remaining two electrons undergo corrosive hydrogen liberation. In contrast, during electropolishing, the four Si electrons are electrochemically active. Lehmann and Gosele ${ }^{10}$ have proposed a different dissolution mechanism that is based on a surface bound oxidization scheme, with hole capture, and subsequent electron injection, which leads to the divalent Si oxidization state. In their discussed mechanism, the Si hydride bonds passivate the Si surface unless a hole is available. This hypothesis is also supported by the experimental observation that hydrogen gas continues to evolve from the porous layer after the applied potential release for a considerable time. The presence of $\mathrm{Si}-\mathrm{H}$ surface bonds during PS formation was also confirmed from spectroscopic studies. ${ }^{11}$

In fact, the electrochemical etching of silicon in aqueous electrolytes is complicated due to the formation and dissolution of intermediate oxides. These processes cause hydrogen gas evolution, and highly branched microporous structures. ${ }^{12,13}$ Also, for the resultant PS layer the structure is highly dependent on the experimental parameters, such as concentration of the HF acid, current density, anodization time, and also, the doping type associated to the carrier concentrations of the silicon wafer. ${ }^{5,6,8,12}$ In addition, another parameter that affects the properties of the PS formed layer that has received little attention are the electrolyte additives. These additives on HF solution work as surfactants and play an important role increasing the mobility at the silicon surface. In the anodic dissolution process, it is known that hydrogen gas is released from the silicon surface dissolving. So, if the surface tension is high, the hydrogen gas is effectively trapped on the Si surface. Then, such hydrogen bubbles will mask silicon surface from solution, preventing the etching process. The surface tension reduction promotes two effects of reducing the size of the hydrogen bubbles, and of allowing the formed bubbles to escape more easily from the solution, favoring the PS layer formation..$^{5,14-16}$

Considering all these aspects, the goal of this work is to present the study and discuss the anodization parameter influences on the formed PS macroporous layer. Comparing the colossal publication found in the literature on PS subjects, few reports are dedicated to PS formation from $\mathrm{MeCN}$ additive. So, this contribution becomes interesting to point out and to clarify, with meticulous explanations, the mechanism associate to $\mathrm{MeCN}$ additive that leads to the singular PS pore morphologies presented in this study. To the best of our knowledge, there are no papers in the literature comparing the role between the ethanol and $\mathrm{MeCN}^{17,18}$ additives, as a solvent in HF solutions, in a systematic way and using this large range of parameter variations. The PS morphology and photolumininescence (PL) response were obtained by Scanning Electron Microscopy (SEM) images and Raman Scattering Spectroscopy measurements, respectively.

\section{Experimental}

Porous silicon samples were obtained from n-type silicon wafers, (100) orientation, phosphorus-doped, with resistivity of $1-20$ and $0.3-0.5 \Omega \mathrm{cm}$. The sample dimensions were $20 \times 20 \mathrm{~mm}$ with indium backside ohmic contact. Two different etching solutions were used: $\mathrm{HF}(48 \%)$ : deionized water: ethanol $(95 \%)=(1: 2: 1)$ in volume and $2 \mathrm{~mol} \mathrm{~L}^{-1} \mathrm{HF}$ with $2.4 \mathrm{~mol} \mathrm{~L}^{-1} \mathrm{H}_{2} \mathrm{O} / \mathrm{MeCN}(99 \%)$ solutions.

A Microquimica MQPG-01 potentiostat with two electrode cell was used for the electrochemical oxidation under galvanostatic method. Si wafer was the work electrode while platinum $(\mathrm{Pt})$ disk was used as a counter electrode. The samples were prepared in a Teflon ${ }^{\circledR}$ cell with different current densities and etching times of $11.3 \mathrm{~mA} \mathrm{~cm}^{-2}$ for $60 \mathrm{~min}$ and $56.5 \mathrm{~mA} \mathrm{~cm}^{-2}$ for $10 \mathrm{~min}$, respectively. In this cell, the Si wafer is placed on a metal disk and sealed through an O-ring, so that only the front side of the sample is exposed to the electrolyte. During the electrochemical etching process the n-type silicon wafer was illuminated by a $50 \mathrm{~W}$ halogen lamp, positioned at a distance of approximately $20 \mathrm{~cm}$ from the Si surface samples in the top of anodization cell to supply holes that must by available at the surface. After anodization, PS samples were rinsed with deionized water (DI) and dried under nitrogen gas $\left(\mathrm{N}_{2}\right)$.

\section{Results and Discussion}

To analyze and understand the results, in a careful way, some fundamental explanations about formation 
are requested. Even though it is accepted that the pore formation occurs at surface defects or irregularities, the exact dissolution chemistries of $\mathrm{Si}$ are still in question. With this in mind, different mechanisms for silicon dissolution have been proposed, in which some basic requirements need to be satisfied. ${ }^{7,8,10}$ The mechanism for the oxidation and dissolution of (100) silicon is discussed in light of experimental finding supported by the divalent dissolution mechanism that is, in aqueous solution, initiated by holes supplied from the Si bulk. ${ }^{10}$ The holes concentration may be thermally generated or photogenerated. The dissolution starts by the hole originated within the silicon bulk that migrates to silicon-electrolyte interface which allows the $\mathrm{Si}$ atom attack. The holes are controlled at a certain applied bias or photogeneration (for n-type $\mathrm{Si}$ ). The $\mathrm{Si}-\mathrm{H}$ bond is attacked and a Si-F bond is established. At this point, it is important to remember that the silicon is under anodic bias, which depends on the composition and $\mathrm{pH}$ of the electrolyte, and PS formation is only observed as long as the current density is below of the critical current density, $\mathrm{J}_{\mathrm{PS}}$. The next step to the pore formation occurs due to the high electronegativety of fluoride which destabilized the $\mathrm{Si}-\mathrm{H}$ bond increasing its reactivity, allowing another $\mathrm{F}^{-}$to attack and bond under generation of an $\mathrm{H}_{2}$ molecule with the electron injection into the substrate. Due to the strong polarization effect of the $\mathrm{F}^{-}$, the electron density of $\mathrm{Si}-\mathrm{Si}$ back bonds is lowered and these weakened bonds will be attacked allowing HF to add across them and breaking the $\mathrm{Si}$-Si bond. The remaining surface atoms are bonded to the $\mathrm{H}$ atoms and the silicon tetrafluoride molecule is produced. Removing the Si atom an atomic size dip remains enhancing the surface inhomogeneity because of the changes in the electric field distribution. This argument was supported in the literature, from the chemical composition studies of PS layer, using IR spectroscopy measurements showing that the silicon surface is terminated with hydrogen, although the $\mathrm{Si}-\mathrm{F}(6 \mathrm{eV})$ bond is much strong than $\mathrm{Si}-\mathrm{H}$ bond. ${ }^{7,12,14,18-24}$

Figure 1 shows top view images of typical PS samples prepared by photoelectrochemical oxidation of n-type silicon, etching time of $60 \mathrm{~min}$ and current density of $11 \mathrm{~mA} \mathrm{~cm}^{-2}$. The samples were prepared with two different solutions of HF-ethanol and HF-MeCN, for two types of Si resistivity. HF-ethanol solution was used for samples presented in images (a) and (b) whereas samples of images (c) and (d) were prepared using HF-MeCN. The respective resistivity values were $1-20 \Omega \mathrm{cm}$ for samples (a) and (c); and 0.3-0.5 $\Omega \mathrm{cm}$ for samples (b) and (d). The results for current density of $56.5 \mathrm{~mA} \mathrm{~cm}^{-2}$ and etching time $10 \mathrm{~min}$ are shown in Figure 2 using the similar sample sequences of Figure 1. From these images, some basic observations may be taken a)

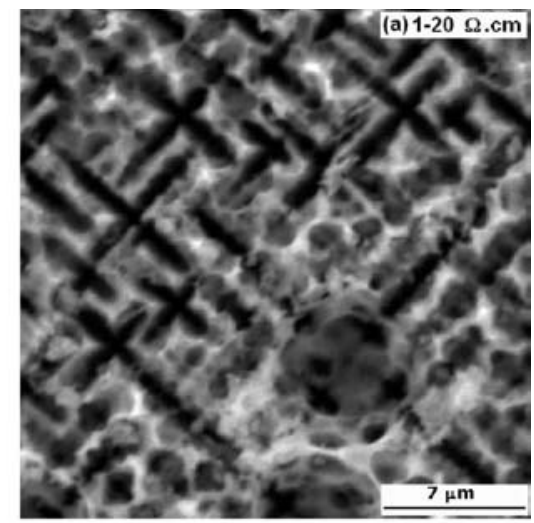

b)
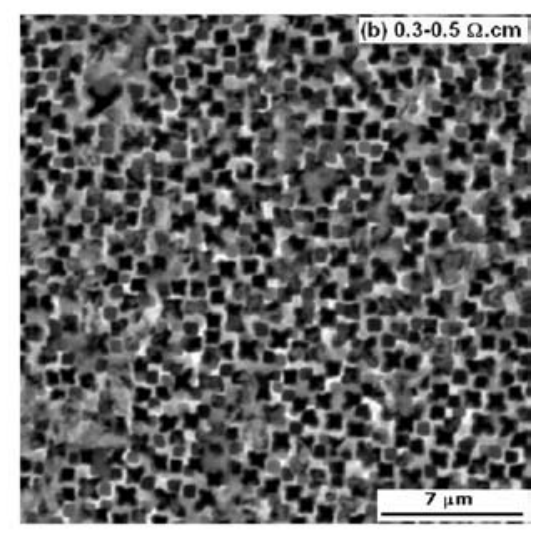

c)

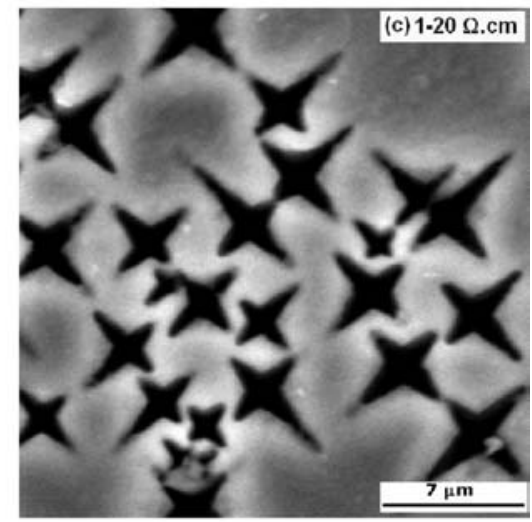

d)

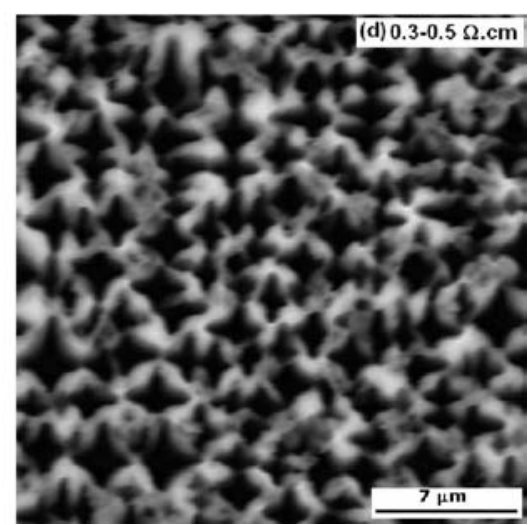

Figure 1. Scanning electron microscopy images of porous silicon samples prepared with etching time of $60 \mathrm{~min}$ and current density of $11 \mathrm{~mA} \mathrm{~cm}^{-2}$, using ethanol (a), (b) and acetonitrile (c), (d) solutions. Two different types of resistivity are also shown: $1-20 \Omega \mathrm{cm}$ for images (a), (c) and $0.3-0.5 \Omega \mathrm{cm}$ for images (b), (d). 
e)

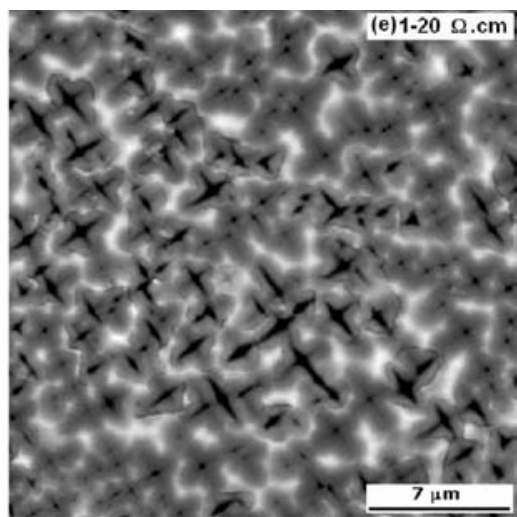

f)

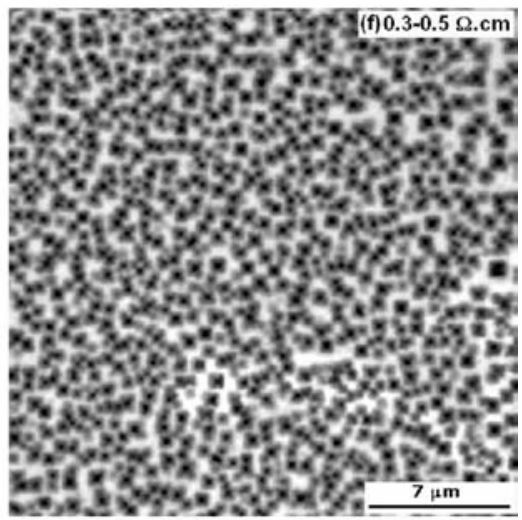

g)

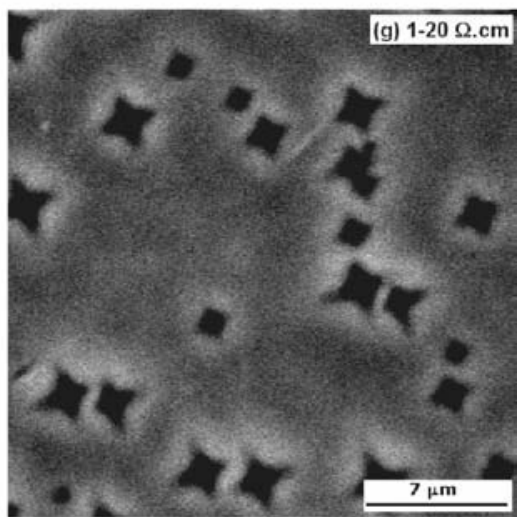

h)

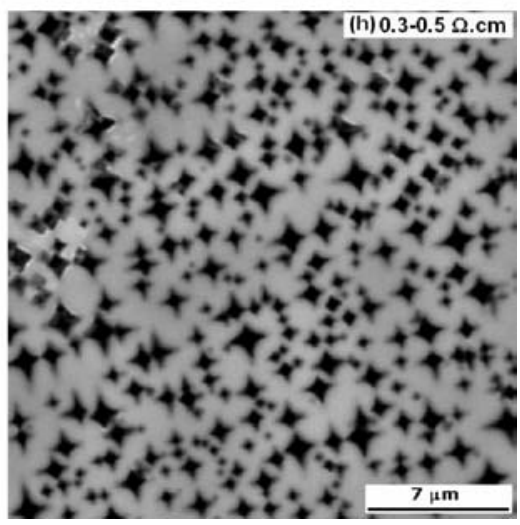

Figure 2. Scanning electron microscopy images of porous silicon samples prepared with etching time of $10 \mathrm{~min}$ and current density of $56.5 \mathrm{~mA} \mathrm{~cm}^{-2}$, using ethanol (e), (f) and acetonitrile (g), (h) solutions. Two different types of resistivity are also shown: $1-20 \Omega \mathrm{cm}$ for images (e), (g) and 0.3-0.5 $\Omega \mathrm{cm}$ for images (f), (h). into account: (i) the shape and size of the macropores are influenced by the silicon wafer doping density, anodization conditions and different solutions; (ii) PS samples formed with lower current density and long periods presented superficial structures more homogeneous than those formed with higher current density and short anodization time; (iii) the pore size of PS layer on (a), (c), (e) and (g) samples with higher resistivity are larger than those of PS layers on (b), (d), (f) and (h) images, with lower resistivity.

From a more detailed investigation, comparing images $1 \mathrm{a}$ and $1 \mathrm{c}$, the porous silicon layer formed in $\mathrm{HF}-\mathrm{MeCN}$ solution is clearly flatter and smoother than that formed in HF-ethanol. The morphology of the porous formed in HF-ethanol present side branches that propagate perpendicularly to their main direction of growth (not shown). Kang et al. ${ }^{25}$ have shown that the MeCN surface tension was greater than that of ethanol and presumed that because their superior surface tension $\mathrm{MeCN}$ molecules would passivate the silicon surface and would prevent its etching process.

As mentioned above, after $\mathrm{Si}-\mathrm{Si}$ bond breaking, the remaining surface $\mathrm{Si}-\mathrm{H}$ produces a hydrophobic silicon surface. However, in aqueous HF solution, the competition of $\mathrm{OH}^{-}$with $\mathrm{F}^{-}$reduces the reactivity of silicon intermediates, reducing the polarization of the remaining silicon bonds. As a consequence, the stability of the Si-Si backbonds increases. According to Rieger et al.,${ }^{12}$ the etching of $\mathrm{Si}$ in aqueous electrolytes leads to a formation of oxide intermediates promoting site deactivations and, then, the etching process proceeds at sites less dependent of the structure, more susceptible to chemical attack. In comparison, if we assume that $\mathrm{MeCN}$ passivates the surface and forms hydride bonds, the preferential etching will occur at locations where Si-F bond exist. According to this, the PS layer formed in HF-MeCN may be more uniform than that prepared in HF-ethanol. If we turn now our attention to Figure 1a and $1 \mathrm{~b}$ at different resistivity, it is easy to predict, by comparison with Figure 1c and Figure 1d, that the substrate doping has some influence on PS formation. It is important to remember that silicon wafer defects increases with the resistivity decrease. The defects or irregularities are expected to produce a random distribution of active sites in the region of semiconductorelectrolyte that, at the beginning of anodization process, may result in the localization of the current flow and the initiation of pores formation.

The morphology dependence of the doping density becomes more apparent at different current density of $56.5 \mathrm{~mA} \mathrm{~cm}^{-2}$, as may be seen by comparing the two sets of Figures 2e, 2f and Figures 2g, 2h. Lehmann et al. ${ }^{26,27}$ have reported that the doping density of the 
substrate determines the pore initiation and also the pore tips, which will be formed in the beginning of anodization process. They discussed that with the control of pore density, it is possible to control the shift of PL peak energy which was demonstrated by the quantum size effect. In addition, the current density also plays an important role in the etching process. With the aqueous HF etching solutions, two etching regimes exist and are limited either by charge density transfer or by ionic diffusion. The transition between these regimes is characterized by a specific current density, $\mathrm{J}_{\mathrm{PS}}$. At $\mathrm{J}<\mathrm{J}_{\mathrm{PS}}$ pores are formed. In the low current density the holes are depleted at the electrode and HF accumulates on the electrode surface. At $\mathrm{J}>\mathrm{J}_{\mathrm{PS}}$ electropolishing process of the silicon surface occurs. So, the pore size is dependent on the depletion layer width and on the mechanism of charge transfer. When the current density increases for highly doped substrates, the inhomogeneties may enhance the local electric field, which works as active sites. This mean that any active site may allow the holes is consumed resulting in a local dissolution. Besides, Lehmann et al. ${ }^{19}$ argued that the current density passing through the electrode surface is related to the dissolution rate. This becomes apparent if the pore formations are compared at different resistivities. Figure $2 \mathrm{~g}$ and $2 \mathrm{~h}$ show PS formed at different resistivitis and current density of $56.5 \mathrm{~mA} \mathrm{~cm}{ }^{-2}$ for etching time of $10 \mathrm{~min}$. While the pore shape did not present significant changes the pore density increased drastically.

Measures of the Raman spectroscopy in the range of 300 up to $8,000 \mathrm{~cm}^{-1}$ were carried out in order to study the structure of PS layers produced by anodization using $\mathrm{HF}$ solution with $\mathrm{MeCN}$ or ethanol and n-type $\mathrm{Si}$ samples. PL spectra corresponding to samples prepared in each solution with the same anodization conditions,

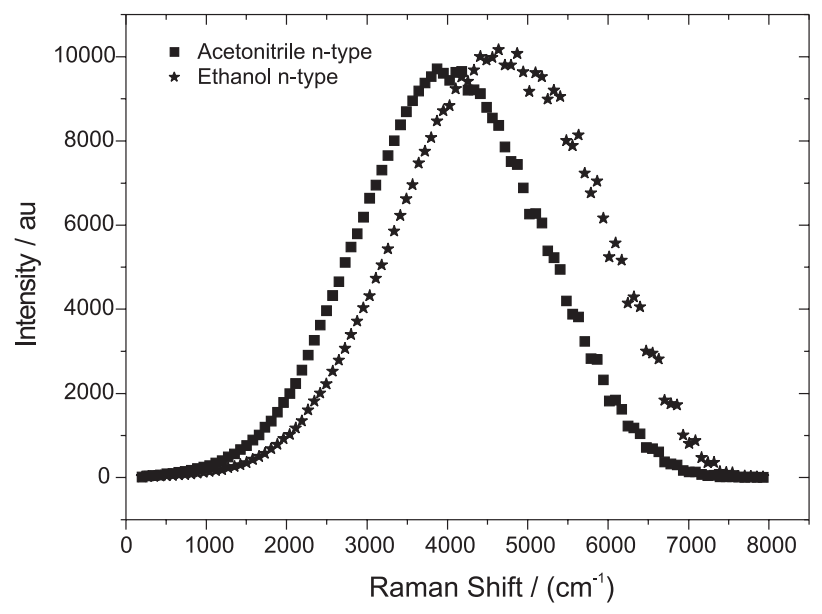

Figure 3. Photoluminescence measured in visible region of the spectrum for PS sample obtained with different solutions on n-type silicon, $1-20 \Omega \mathrm{cm}$, with current density of $56.5 \mathrm{~mA} \mathrm{~cm}^{-2}$. current density (56.5 $\mathrm{mA} \mathrm{cm}^{-2}$ ), anodization time (10 min) and resistivity 1-20 $\Omega \mathrm{cm}$, are shown in Figure 3. PL spectrum for sample produced from HF-MeCN solution presented a blue shift peak that may depend on the pore depth and diameter. However, is not clear which pore contribution is dominant for this shift: depth or diameter. According to the literature, ${ }^{28}$ the PL peak from PS generally exhibits a blue shift with increasing the resistivity of $\mathrm{Si}$ wafer. It has also been shown that PS porosity increase may lead to a blue shift of the PL peak which was demonstrated by quantum size effect. Therefore, the appearance of the PL peak blue shift depends not only on the resistivity but also on the Si wafer crystallinity.

Figure 4 shows the thickness (pore-depth) of PS layer for the two solutions (ethanol/MeCN), using 1-20 $\Omega \mathrm{cm}$ Si wafers with current density of $56.5 \mathrm{~mA} \mathrm{~cm}^{-2}$. The pore morphology shows few general trends. The thickness of PS layer prepared in HF-Ethanol solution is thicker than the sample formed in $\mathrm{HF}-\mathrm{MeCN}$ solution. On the other hand, the average diameter of the pores obtained using HF-MeCN is higher than those obtained using HF-ethanol. The morphology of the pores is time dependent and change from narrow branched pores (in HF-MeCN) to unbranched ones (in HF-ethanol) (not shown). It was observed a constant aspect ratio for samples produced in HF-ethanol, but the same behavior is not observed for samples produced in HF-MeCN. In summary, our experiments demonstrated that with the anodization time increase the pore-depth increases for PS formed in HF-ethanol while for PS formed in HF-MeCN additive the pore diameter increases. In essence, as long as the chemical processes are fast enough, the pore diameter and depth may be modulated as a function of time in HF-MeCN and HF-ethanol, respectively. These

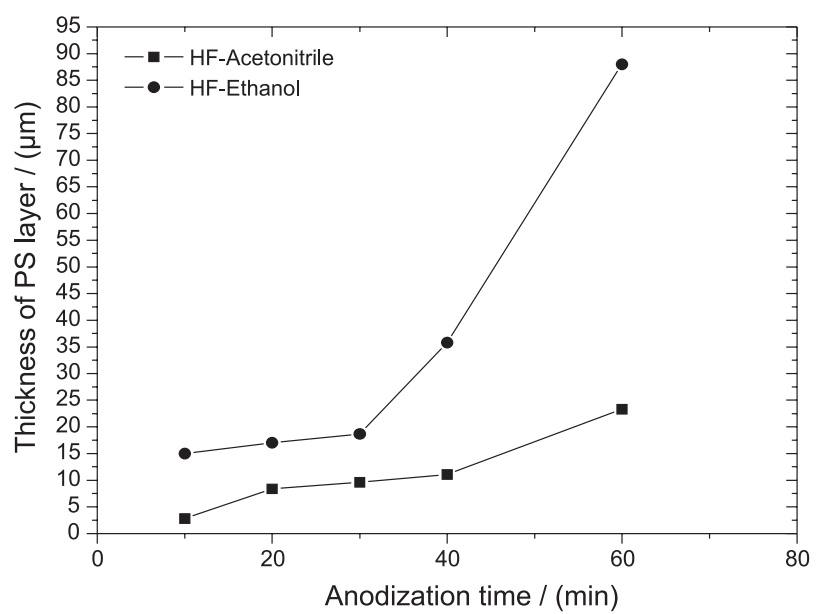

Figure 4. PS layer thickness as a function of anodization time using $1-20 \Omega \mathrm{cm}$ and n-type silicon wafer, with different solutions, for current density of $56.5 \mathrm{~mA} \mathrm{~cm}^{-2}$. 
results are promising by its new feature and might be useful for important applications that require specific pore sizes and shapes, such as visible optoelectronic devices. Nonetheless, a better understanding of the dynamics of pore growth is necessary for its rigorous control.

\section{Conclusions}

We discussed that PS pore formation is under a wide range of experimental conditions and must be understood in a large context including a large number of parameter contributions. Nonetheless, some general trends may be derived from this work. We prepared porous silicon on Si substrates by electrochemical etching of silicon in HF-MeCN and in HF-ethanol. Two different resistivities were employed to produce PS layers. SEM images revealed a PS surface formed by macropores with different shapes and sizes that change with the nature of the electrolyte, anodic current density, and resistivity of the silicon wafer. PS layer formed in HF-MeCN solution shows a much more homogeneous and uniform distribution of pores. Differences in the thickness were also observed. Pore-depth shows a strong dependence with the solution used. It is observed that the density of PS increased with increasing the Si doping level. The PL peak shifted to the blue region for PS prepared with MeCN solution. This behavior may be associated to the reduction of the crystallites size for this attack compared with the same one produced by HF-ethanol.

\section{Acknowledgments}

The authors would like to thank CNPq (Process 141221/2005-4) for the financial support. We are also grateful to M. L. Brison by SEM images. Special thanks to LME/LNLS, Campinas, by providing the facilities of SEM analysis.

\section{References}

1. Canham, L. T.; Appl. Phys. Lett. 1990, 57, 1046.

2. Anderson, R. C.; Muller, R. S.; Tobias, C. W.; Sens. Actuators A 1990, 23, 835 .

3. Searson, P. C.; Appl. Phys. Lett. 1991, 59, 832.

4. Mazzoleni, C. ; Pavesi, L.; Appl. Phys. Lett. 1995, 67, 2983.

5. Bomchil, G.; Herino, R.; Barla, K.; Pfister, J. C.; J. Electrochem. Soc. 1983, 130, 1611 .
6. Propst, E. K.; Rieger, M. M..; Vogt, K. W.; Kohl, P.; Appl. Phys. Lett. 1994, 64, 1914.

7. Bisi, O.; Ossicini, S.; Pavesi, L.; Surf. Sci. Rep. 2000, 38, 1.

8. Beale, M. I. J.; Benjamin, J. D.; Uren, M. J.; Chew, N. G.; Cullis, A.G.; J. Cryst. Growth. 1985, 73, 622.

9. Lehmann, V.; Foll, H.; J. Electrochem. Soc. 1990, 137, 653.

10. Lehmann, V.; Gosele, U.; Appl. Phys. Lett. 1991,58, 856.

11. Peter, L. M.; Blackwood, D. J.; Pons, S.; Phys. Rev. Lett. 1989 , $62,308$.

12. Rieger, M. M.; Kohl, P. A.; J. Electrochem. Soc. 1995, 142, 1490.

13. Turner, D. R .; J. Electron. Mater. 1958, 105, 402.

14. Gosálvez, M. A.; Sato, K.; Foster A. S.; Nieminen, R. M.; Tanaka, H.; J. Micromech. Microeng. 2007, 17, S1.

15. Yang, C. R.; Chen, P. Y.; Chiou, Y. C.; Lee, R. T.; Sens. Actuators A 2005, 119, 263.

16. O’Halloran, G.M.; Kuhl, M.; Trimp, P.J.; French, P.J.; Sens. Actuators A 1997, 61, 415.

17. Propst, E. K.; Kohl, P. A.; J. Electrochem. Soc. 1994, 141, 1006.

18. Ponomarev, E. A.; Lévy-Clement, C.; Electrochem. Solid-State Lett. 1998, 1, 42.

19. Lehmann, V.; Thin Solid Films 1995, 255, 1.

20. Carstensen, J.; Christophersen, M.; Föll, H.; Mater. Sci. Eng. B 2000, 69-70, 23.

21. Lehmann, V.; Electrochemistry of Silicon Instrumentation, Science, Materials and Applications, Wiley-VCH: Weinheim, 2002.

22. Gole, J. L.; Dudel, F. P.; Seals, L.; Reiger, M.; Kohl, P.; Bottomley, L. A.; J. Electrochem. Soc. 1998, 145, 3284.

23. Beale, M. I. J.; Chew, N. G.; Uren, M. J.; Cullis, A.G.; Benjamin, J. D.; Appl. Phys. Lett. 1985, 46, 86.

24. Föll, H.; Christophersen, M.; Carstensen, J.; Hasse, G.; Mater. Sci. Eng. 2002, R280, 1.

25. Kang, C. G.; Kang, M. S.; Yang, J. H.; Jin, J. H.; Hong, S. I.; Min, N. K.; J. Korean Phys. Soc. 2003, 42, S693.

26. Lehmann, V.; Stengl, R.; Luigart, A.; Mater. Sci. Eng. B 2000 , 69-70, 11

27. Gosele, U.; Lehmann, V.; Mater. Chem. Phys. 1995, 40, 253.

28. Feng, Z. C.; Surf. Coat. Technol. 2006, 200, 3254.

Received: September 28, 2007

Web Release Date: April 30, 2008

FAPESP helped in meeting the publication costs of this article. 